OPEN ACCESS

Edited by:

Jože Rugelj,

University of Ljubljana, Slovenia

Reviewed by:

Cesar Collazos,

University of Cauca, Colombia

Camino Fidalgo,

University of Zaragoza, Spain

*Correspondence:

António Coelho

acoelho@fe.up.pt

Specialty section

This article was submitted to

Human-Media Interaction,

a section of the journal

Frontiers in Computer Science

Received: 28 January 2020

Accepted: 03 July 2020

Published: 31 August 2020

Citation:

Coelho A, Rodrigues $R$, Nóbrega $R$ Jacob J, Morgado L, Cardoso P, van

Zeller M, Santos $L$ and Sousa $A A$

(2020) Serious Pervasive Games.

Front. Comput. Sci. 2:30.

doi: 10.3389/fcomp.2020.00030

\section{Serious Pervasive Games}

\author{
António Coelho ${ }^{1,2 *}$, Rui Rodrigues ${ }^{1,2}$, Rui Nóbrega ${ }^{2,3}$, João Jacob ${ }^{1}$, Leonel Morgado 2,4, \\ Pedro Cardoso ${ }^{1,2,5}$, Maria van Zeller ${ }^{1}$, Liliana Santos ${ }^{1}$ and A. Augusto Sousa ${ }^{1,2}$
}

${ }^{1}$ Faculdade de Engenharia, Universidade do Porto, Porto, Portugal, ${ }^{2}$ INESC TEC, Porto, Portugal, ${ }^{3}$ NOVA LINCS, Faculdade de Ciências e Tecnologia, Universidade Nova de Lisboa, Lisbon, Portugal, ${ }^{4}$ Universidade Aberta, CIAC, \& LE@D, Coimbra,

Portugal, ${ }^{5}$ Faculdade de Belas Artes, Universidade do Porto, Porto, Portugal

Serious Pervasive Games extend the magic circle (Huizinga, 1938) to the players' context and surrounding environment. The blend of both physical and fictive game worlds provides a push in player engagement and promotes situated learning approaches. Space and time, as well as social context, acquire a more meaningful impact on the gameplay. From pervasive learning towards science communication with location-based games, this article presents research and case studies that exemplify their benefits and related problems. Pervasive learning can be defined as "learning at the speed of need through formal, informal and social learning modalities" (Pontefract, 2013). The first case study - the BEACONING project-aims to contextualize the teaching and learning process, connecting it with problem-based game mechanics within STEM. The main goal of this project is to provide the missing connection between STEM subjects and real-world interactions and applications. The pedagogical foundation is supported on problem-based learning (PBL), in which active learning is in the center, and learners have to work with different tools and resources in order to solve problems (quests). Teachers create, facilitate, and assess pervasive and gamified learning activities (missions). Furthermore, these quests are gamified in order to provide non-linear game plots. In a second case study, we demonstrate and evaluate how natural heritage can benefit from pervasive games. This study is based on a set of location-based games for an existing natural park, which have been developed in order to provide enhanced experiences, as well as additional information about some species that are more difficult to observe or that are seasonal. Throughout the research and development of these projects, we have encountered and identified several problems, of different nature, present in pervasive games.

Keywords: serious pervasive games, pervasive games, serious games, location-based games, pervasive learning, science communication

\section{INTRODUCTION}

Games can be considered a cultural media, and source of formative experiences, in the broad definition of "Ludification of Culture" (Raessens, 2006).

Serious games take advantage of the potential of games to abstract and simplify reality and engage players in activities other than entertainment (Sawyer and Rejeski, 2002). However, games are also played as a closed formal system, called the magic circle (Huizinga, 1938). This concept was later adapted to digital games by Salen and Zimmerman (2004). This promotes disengaging from reality, suspension of disbelief, which amplifies the potential to generate learning and behavior 
change. Although this can be good for many serious games applications, by focusing on the essential aspects of the intended experience, it may fail in other cases. This is the case when the focus of the player should be in the surrounding objects, as in a museum visit, for example. In this case, the game should not disengage the visitor from the primary focus on the museum experience.

Pervasive games extend this magic circle to the real world, exploring the context of the player (Montola, 2005; Montola et al., 2009). These games combine features of ubiquitous gaming and live role-playing games (Falk and Davenport, 2004). This type of pervasiveness significantly differs from the area it is inspired from, pervasive computing (Nieuwdorp, 2007). In the case of pervasive games, context can be related to the players' profile, location, time of play, or other related information such as the weather or calendar events. Considering a serious game for learning, for example, the learning process occurs in distinct times and places, either in school or at home, but also with friends when and where is more convenient. Serious games for learning should take into consideration this situation to promote the best learning activities for all these distinct contexts. In class, the teacher can introduce competitive or collaborative dynamics to encourage individual or group activities; at home, different actors and dynamics can be introduced, involving friends and family, personal backgrounds, and space. The intersection of Serious Games and Pervasive Games defines the concept of Serious Pervasive Games. Arango-López et al. (2017) define its concept as "A pervasive game delivers to the player an enriched experience of game through an evolvement of the dynamics of the game, expanding the space of the game according to the context where it is played. This allows breaking the boundaries of the game world, making reality part of it and that the elements in that reality have an influence during the game."

This article presents two case studies that take advantage of serious pervasive games to promote learning "anytime and anywhere" (Section Pervasive Learning), with a concrete case of communicating science in natural parks (Section Pervasive Games in Science Communication for Natural Parks). Section Issues in Serious Pervasive Games provides a discussion of the issues that must be taken into consideration when designing serious pervasive games, and the last section presents some conclusions and future challenges.

\section{PERVASIVE LEARNING}

Pervasive learning has its roots in mobile learning (m-learning), which refers to learning facilitated by mobile devices. The primary aim of m-learning is to provide users with a learning environment that is not restricted to a specific location or time (Laine and Joy, 2009).

Pervasive learning pushes m-learning a little further, using pervasive computing for increased immersion in the learning process. Pervasive learning is an immersive experience that mediates between the learner's mental (e.g., needs, preferences, prior knowledge), physical (e.g., objects, other learners), and virtual (e.g., content accessible with mobile devices, artifacts) context. The intersection of these contexts is referred to as a pervasive learning environment (Syvänen et al., 2005).

\section{Related Work}

Felipe et al. (2018) accounts for early efforts to develop a methodology for creating pervasive serious games, extending a methodology called Process Model for Development of Serious Games, by leveraging the development case of a serious games for learning of computer networking. Arango-López et al. (2019) focus on the narrative and geolocation applied to close spaces for an enriched experience to the player. The related work presents a very good review on frameworks for developing pervasive games and, as a main contribution, describes the creation of a platform that integrates tools for creating stories and editing narrative content in the game experiences. Several other studies have also focused on specific Software Engineering techniques for pervasive games (Valente and Feijó, 2014; Viana et al., 2014; Valente et al., 2017).

Santos and Burguès (2017) investigated authoring of Chronica Mobilis, a serious pervasive game for raising awareness and discussion of social, political, and historical uses in contemporary cities, via Chronica Mobilis, a situated experience about gentrification, by placing players amid conflict. They detail design aspects to balance narrative and ludology, with a method that combines scripting, design, and implementation, integrating production and dissemination roles as co-creative.

Arango-López et al. (2018) present a systematic review of the literature on the results of pervasive learning games, identifying different research projects that improve the learning process. A recent survey (Lima et al., 2020) of problems and contributions in the field of m-learning demonstrated that research effort is mostly focused on creating activities and monitoring them, and somewhat on exploring new technologies for assessing their possibilities. It also established that there is a lack of research on structural and logistics aspects, and on assessment aspects of m-learning, which are essential components of large scale, regular deployment of learning activities in formal education. Efforts to collect data from serious pervasive games while they are ongoing, as part of educational information systems such as those developed for BEACONING (detailed in the next section), are thus critical for widespread adoption of these games by educational systems.

An example of a game that was developed for pervasive learning is the EduPark app. This game-like application (app) is an interactive, interdisciplinary quiz with $A R$, based on Geocaching principles, intended to be played in a specific urban park (Carvalho and Guimarães, 2018). The EduPARK project followed a framework proposed by Parker (2011), since it allows developing enhanced learning environments comprising various cycles of refinement of the prototype (Carvalho and Guimarães, 2018). The game Savannah allows learning about lions' behavior through collaboration between players, thus exploring a more educational component (Benford et al., 2004).

Finde Vielfalt Simulation is a simulation game for school classes from grade 7 . As the players get pulled into a story, they have to solve tasks to discover biodiversity, in real nature location places, while dealing with the dilemma between economic 
interest and nature conservation. Schaal et al. (2018) showed that playing Finde Vielfalt Simulation had a positive impact on biodiversity-related knowledge and that the players felt closer to nature after playing it.

Games have another very relevant characteristic, which is the fact that information on gameplay (game metrics/analytics) can be used also as indicators for the efficiency end efficacy of learning. Taborda et al. (2019) present a systematic literature review on the effectiveness and fun metrics in a pervasive game experience. The main conclusions show that only a few metrics were identified, so there is a need for further study in this area in order to improve the user experience. This topic is further explored in Martinez-Ortiz et al. (2019) as part of the BEACONING platform, in the next section.

\section{The BEACONING Project}

The BEACONING project (Bourazeri et al., 2017) was designed to address the needs of pervasive learning, as reflected in the full name of the project: "Breaking Educational Barriers with Contextualized, Pervasive and Gameful Learning." It was focused on "anytime, anywhere" learning by exploiting pervasive, context-aware, and gamified techniques and technologies, framed under the Problem-Based Learning approach. This project was concluded in April 2019 and achieved the following results:

- Integrated BEACONING ecosystem: a cloud-based modular platform that supports the delivery of integrated learning. This platform provides a set of core services and tools that integrate the whole community in a gamified workflow. Game designers create games to foster the learning activities, organized by educators, that make them available to teachers to deploy to the students.

- Gamified Lesson Path (GLP): the core of the BEACONING Project and experience. The GLP [Bourazeri et al.] embeds learning in the daily life of the students, while providing deep engagement through their Game Plots overlaid over the pedagogical content. The game plot is the game narrative that drives the student in the learning activity. The game plot can include adventures and/or location-based narratives. On top of this game plot, the teachers integrate the gamified learning activities (missions) and the specific challenges (problems) to solve (quests), including the analytics that provide feedback to the teacher about the students' performance (Figure 1).

- BEACONING Platform GUI: graphical user interfaces (GUIs) used in the BEACONING Platform form the front-end user experience (UX) for important stakeholders such as the Teacher and the Students. Teachers can select and edit the GLP that they find more useful for their classes and deploy them at the most appropriate time. Through a dashboard, the teachers can monitor the progression of the students' activities and their performance (Figure 2), being able to adapt the GLP for each student according to their needs. The students have their dashboard that allows them to be aware of the missing activities and get feedback on their progress and performance.

- Authoring tool: The authoring tool (Cardoso et al., 2020) is also a core component as it allows the creation and editing of the GLP, integrating the pedagogical contents with the game plots. So, its architecture integrates most of the BEACONING components, and the GUI is intuitive and based on a visual paradigm (Figure 3) in order for a teacher to understand how the game plot will drive the educational activities. The tool sets up the mini-games (quests) that drive the educational content (missions) and assigns them to the events of the game plot. Finally, it submits the GLP to the core services, in order to make it available for the teachers to deploy it to the students.

- Game plot editor: Game plots can be created by game companies using this tool, making new game plots available for instructional design of GLP. Although a more specific tool, this game plot editor is meant for anyone with knowledge on game design to implement the game mechanics and level design without any knowledge of programming (Figure 4).

- Learning Analytics: The BEACONING ecosystem provides educational activities as GLP instances. These activities generate a comprehensive set of analytics that are available for teachers to monitor students' performance (Martinez-Ortiz et al., 2019). The analytics are defined on the authoring tool at the time of the learning design. This enables the teacher to get analytics already integrated in the GLP as they deploy it.

\section{An Example of a Beaconing Pervasive Learning Activity}

A set of large-scale pilots of the BEACONING ecosystem was carried out throughout Europe on February 10, 2018. In Portugal, the authors created an activity at the University of Porto's Botanical Garden. This activity was focused on exploring scientific content in botany, along with a story that embraced the literary work of Sophia de Mello Breyner Andresen, a celebrated Portuguese writer whose grandparents lived in this house at the beginning of the 20th century (thus a place which played a role in her work). With this in mind, the authors explored events and the lore in "O Rapaz de Bronze" (The Bronze Boy) in a way for the visitors (the players) to be able to travel through the Garden and explore its diversity. Guided through this story, this activity was composed of seven sequential challenges, each located in a particular Point of Interest (POI), in which the former challenges triggered clues for the players to find the next (Figure 5). Within a predefined radius, each POI presented players with particular challenges, consisting of different minigames, from puzzles to quizzes, action games, riddles, and friendly conundrums (Figure 6), based on a visit we had first undertook with Garden's staff.

The overall activity valued the presence of the players in loco, meaning that many of the challenges (Figure 7) were focused on inspecting players' actual physical surroundings, sometimes requiring them to take their sensorial perception into account to progress. The goal was to make visitors engaged with the Garden itself, exposing them to academic content that could be witnessed or experienced there. Ergo, blending the content of the game with the content of the Garden transformed its space into the space of the game itself, and it was by merging these two spaces that this activity was successful in promoting experiential learning.

At the end, we surveyed 19 random players. Despite some issues, we found that about $79 \%$ of the interviewees found the experience rewarding at a scientific level, around $83 \%$ found 


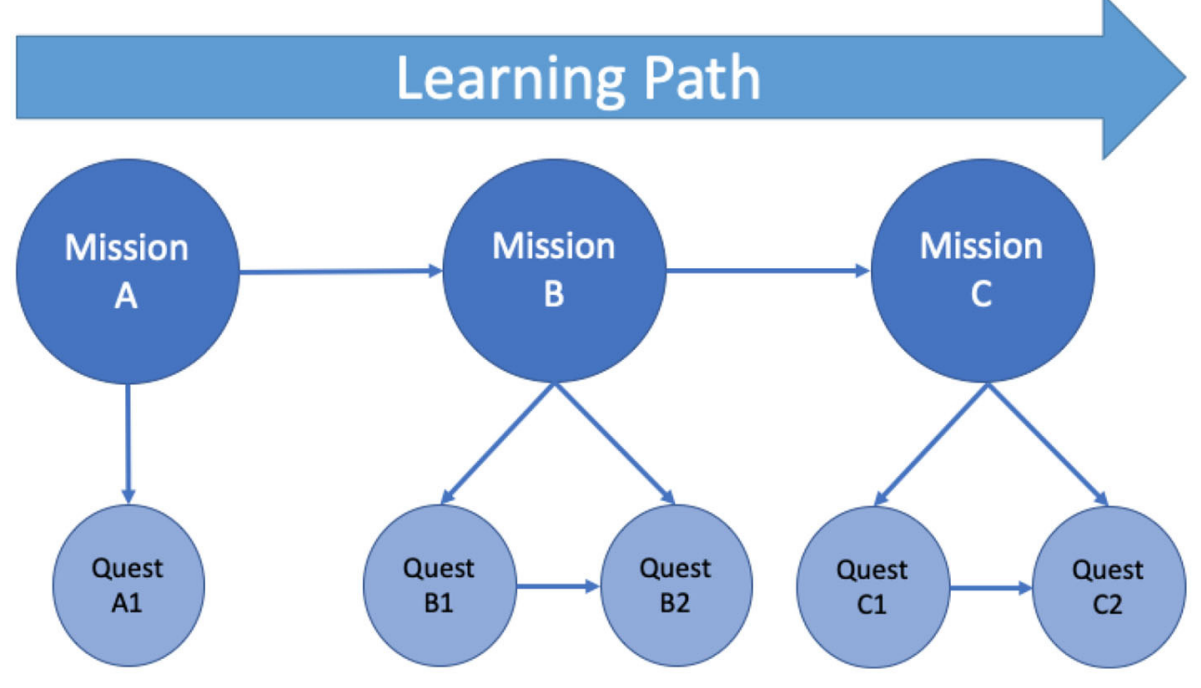

FIGURE 1 | Learning path leveling up - a meta-game narrative/story contextualizes the missions and quests (Arnab et al., 2016).

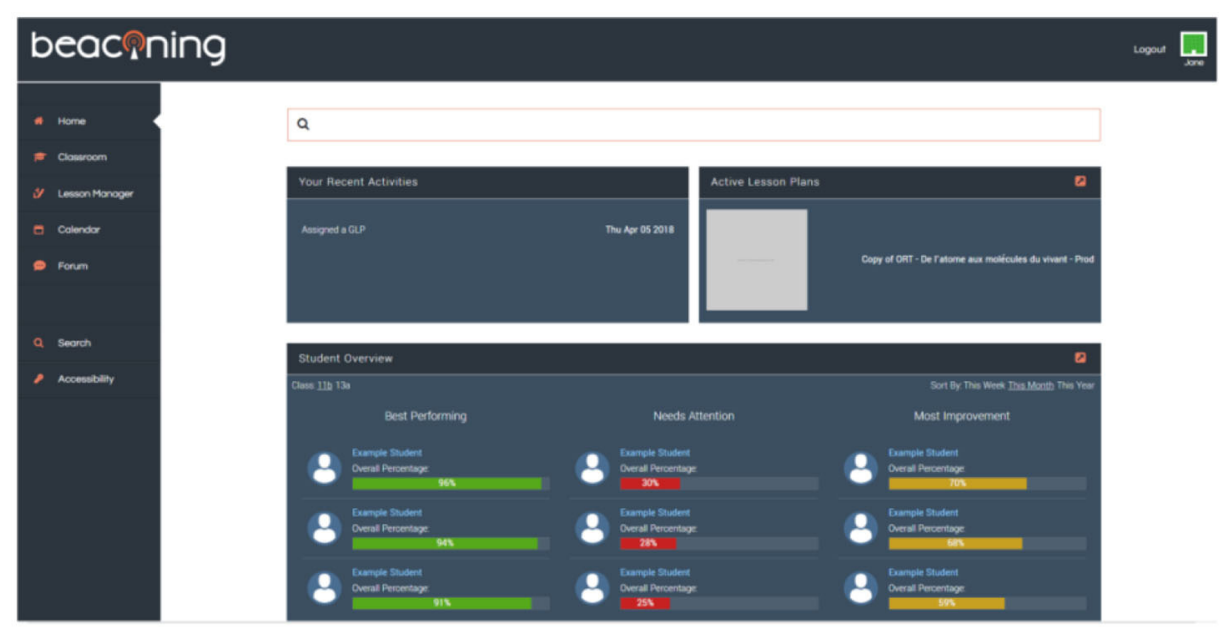

FIGURE 2 | GUI: Teacher dashboard ${ }^{1}$.

that the games made the experience more fun, and about $95 \%$ understood that the mini-games helped them learn the content.

\section{PERVASIVE GAMES IN SCIENCE COMMUNICATION FOR NATURAL PARKS}

Pervasive serious games allow amplifying and enriching the experience of visiting nature parks since a layer of digital information augments our perception of the real world. This augmentation is quite relevant as animals are generally evasive, and wildlife has biorhythms that are not always suitable for the visitors. As an example, some animals only appear at night,

${ }^{1}$ Beaconing deliverable D4.5 BEACONING Platform GUI, 2018. Available online at: https://beaconing.eu/wp-content/uploads/deliverables/D4.5.pdf. and some flowers can only be seen at specific times of the year (e.g., Spring). Furthermore, the intricacy of ecosystems makes it difficult to communicate, and pervasive games can improve this by providing specific gameplay, at the location of the visitor.

Following this challenge, we have developed a set of prototypes to analyze how serious pervasive games can improve the visitors' experience and the effectiveness of the science communication.

As a first study, we have developed the game of the jay (Santos et al., 2017) that is unlocked in an oak tree forest inside the park. It is a serious game to learn about the vital role the Eurasian jay has on oak tree forest reforestation. The player has to make the jay collect and plant acorns, and collapse clouds to make it rain, in order to put out wildfires and make the sprouts grow (Figure 8). To win, the player must reforest the scenery until the ecosystem can reach the maximum number of oak trees. 


\section{beachning}

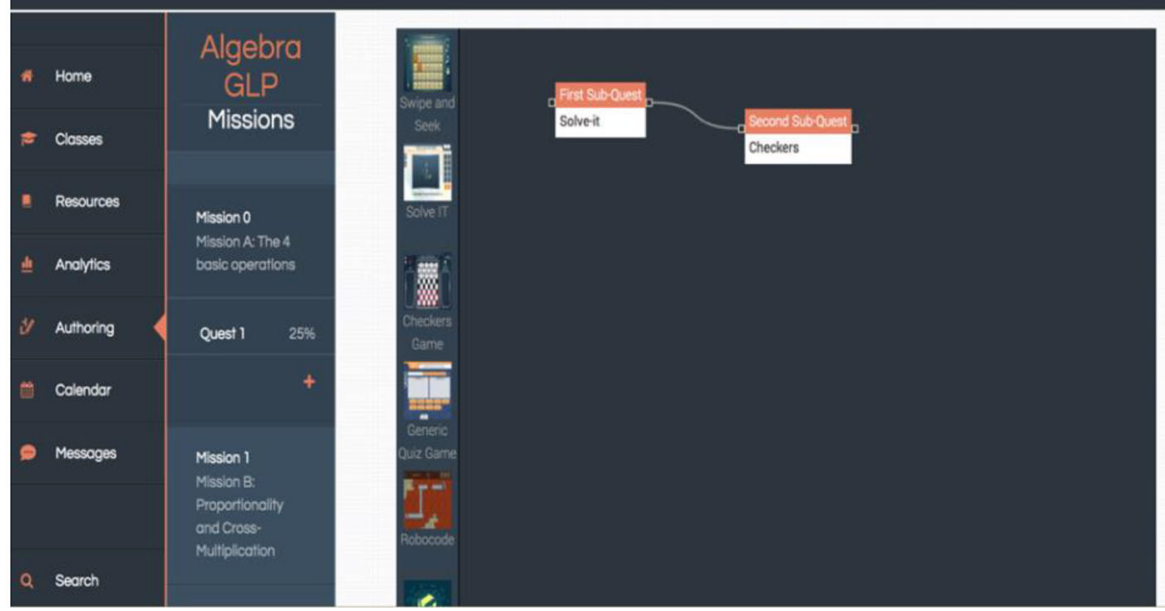

FIGURE 3 | The authoring tool GUI².

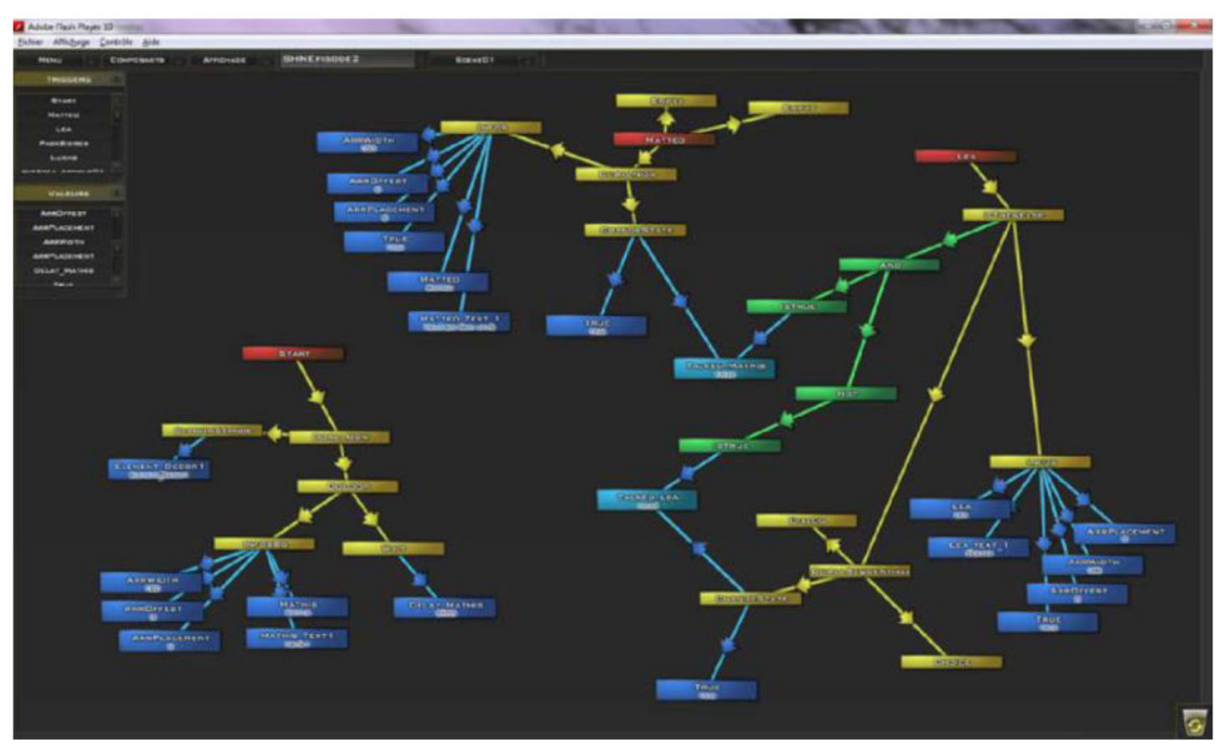

FIGURE 4 | The Game plot editor ${ }^{3}$.

This game took advantage of simple mechanics and abstraction to deliver relevant information on location, about the particular ecosystem the visitor is exploring. A preliminary study performed on location with 56 subjects concluded that the game was effective in communicating the educational content (Santos et al., 2017). From these findings, a decision has been taken to improve the pervasiveness on the next prototype.

\footnotetext{
${ }^{2}$ Beaconing deliverable D4.4 Prototype of the Authoring and Procedural System Framework Component, 2018. Available online at: https://beaconing.eu/wpcontent/uploads/deliverables/D4.4.pdf.

${ }^{3}$ Beaconing deliverable D3.5 Game Design Document, 2016. Available online at: https://beaconing.eu/wp-content/uploads/deliverables/D3.5.pdf.
}

The Virtual Animal Detector (Santos et al., 2016) is a "treasure hunt" and collection game about the animals that live in freedom in a park. Some of them are difficult to see in the wild since they are elusive or can only be seen in schedules not compatible with visits (e.g., at night). With this game, visitors can explore the park and learn more about these species. In the game, a radar detects the approach to a predefined set of coordinates where the animal is found more often, sending a notification to the user. By touching the radar, it displays the information on that species. The player has to find and register information on each species. The user is then able to collect the "sticker" of that species. By gamifying the visit through the 


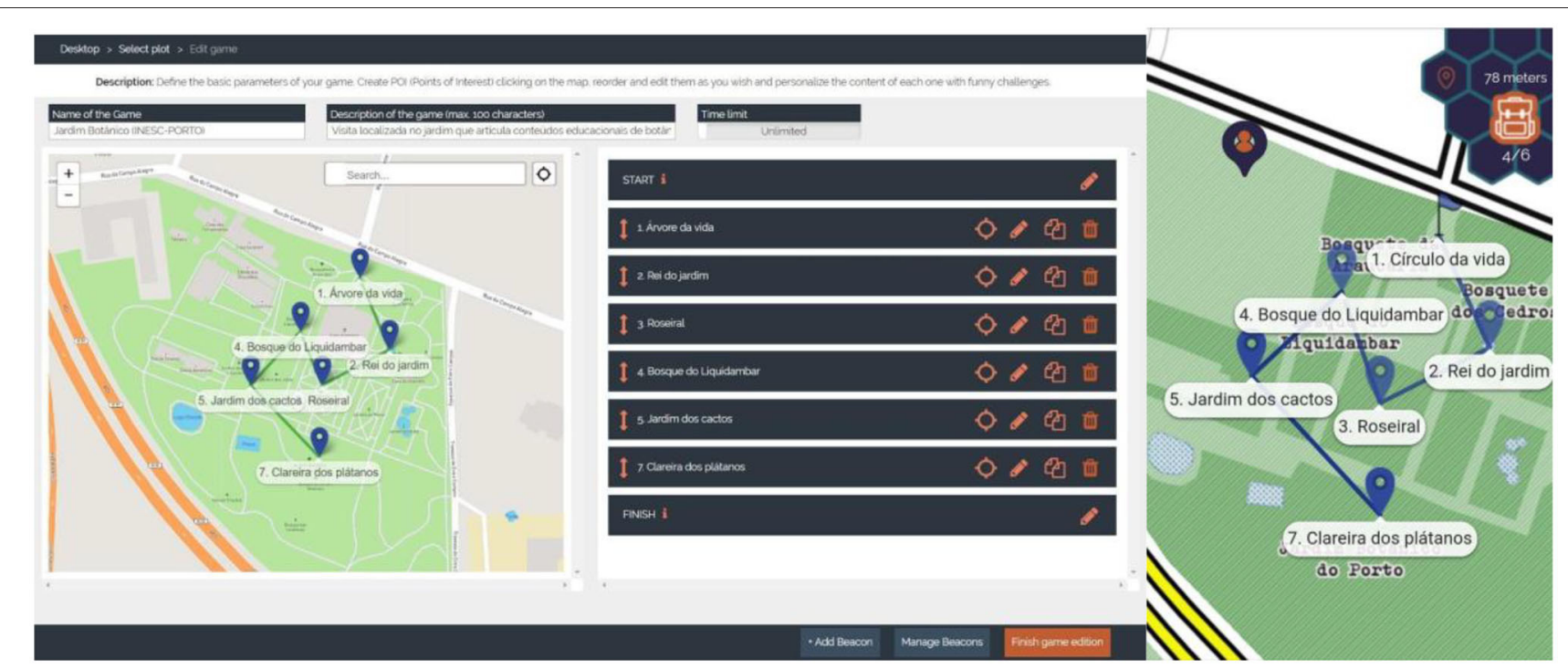

FIGURE 5 | Screenshot of the map displaying the entire path of the activity and the respective Points of Interest (authoring tool on the left; mobile app on the right).

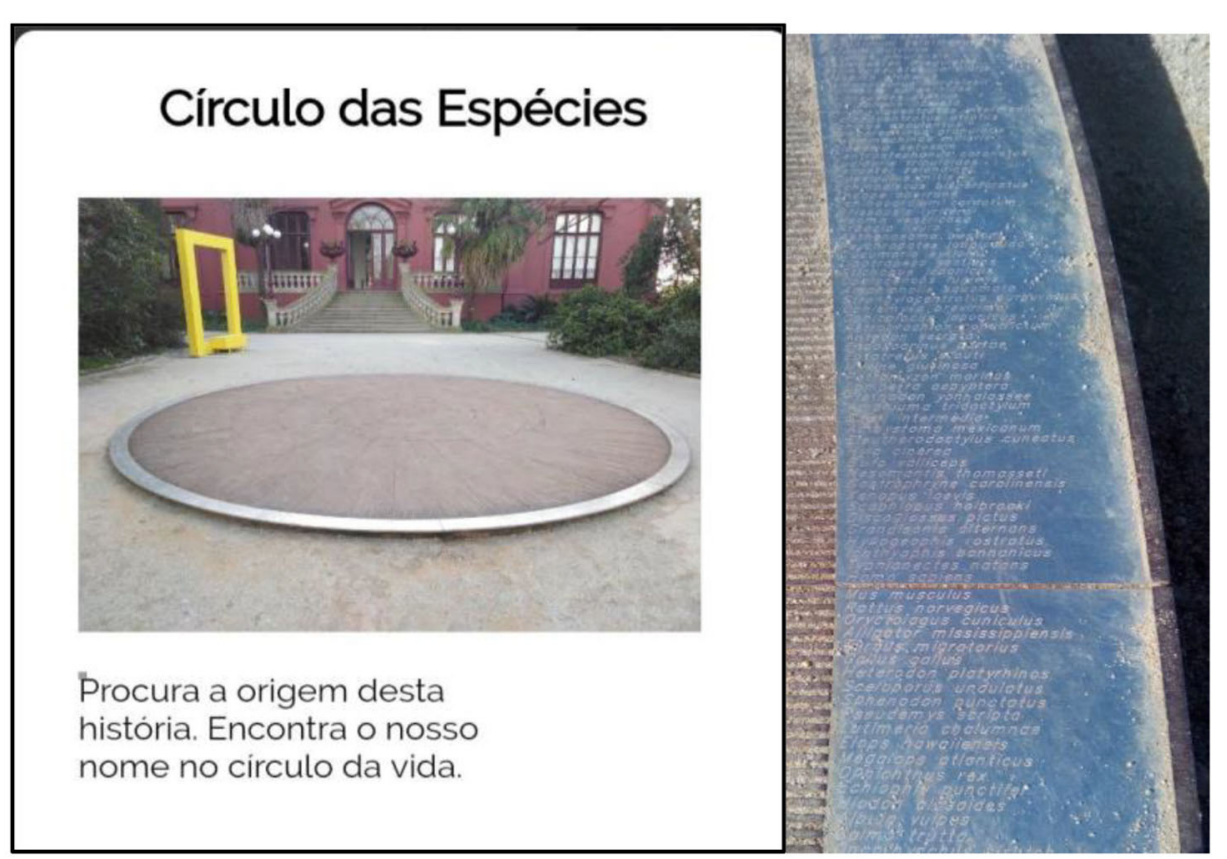

FIGURE 6 | Screenshot and real-world aspects of playing the first challenge, which asks players to find the answer to the riddle in the circle at the entrance of the garden that is a map of the species on Earth. Translation of the picture: "Circle of the Species," "Search the origin of this story. Find our name in the circle of life".

dynamics of a sticker card collection (Coelho and Costa, 2017), the visit becomes more engaging, and a narrative is unveiled to the user as the collectibles are all captured. Curiosity to explore the location is improved by using an engaging GUI (Figure 9) such as the radar metaphor. This approach allows less disengagement from the natural environment by moving the magic circle toward the surrounding environment with a more pervasive application. Nevertheless, some issues about the usability of the mobile application have arisen. Usability is a highly relevant issue for pervasive games as the magic circle expands.

Other mechanics were introduced in this second prototypethe Footprints Memory game (Santos et al., 2017)-where the player learns to recognize some animal species by their footprints. Associations must be made between cards with images of animals and cards with footprint illustrations of those species. The goal is 


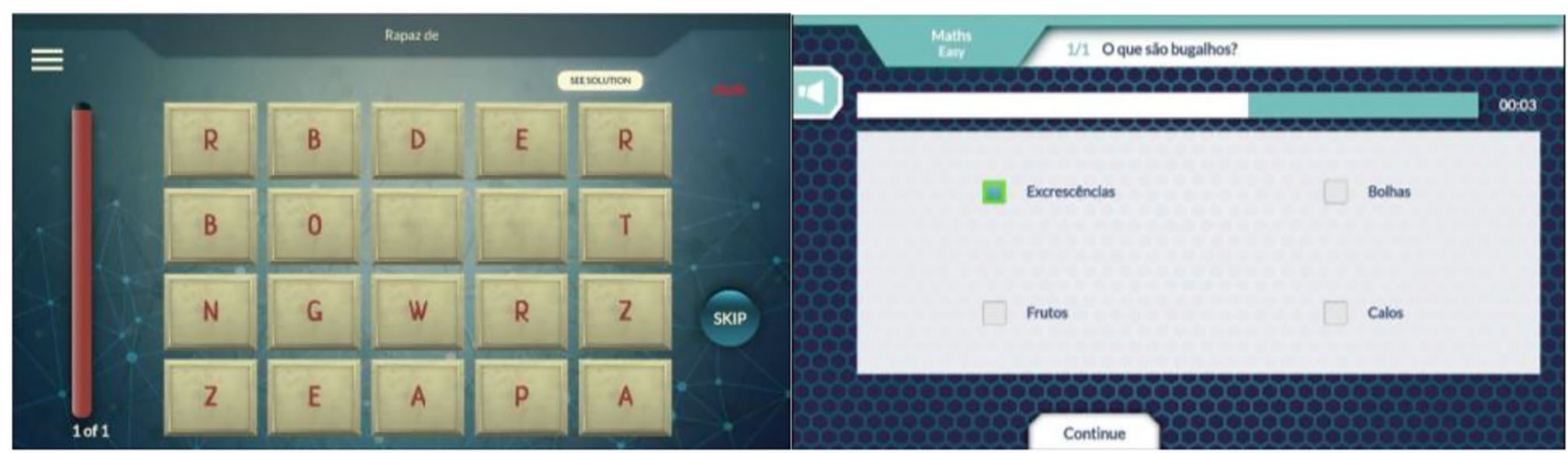

FIGURE 7 | Screenshots of two mini-games encountered in POI and actual ongoing activity within the garden space.

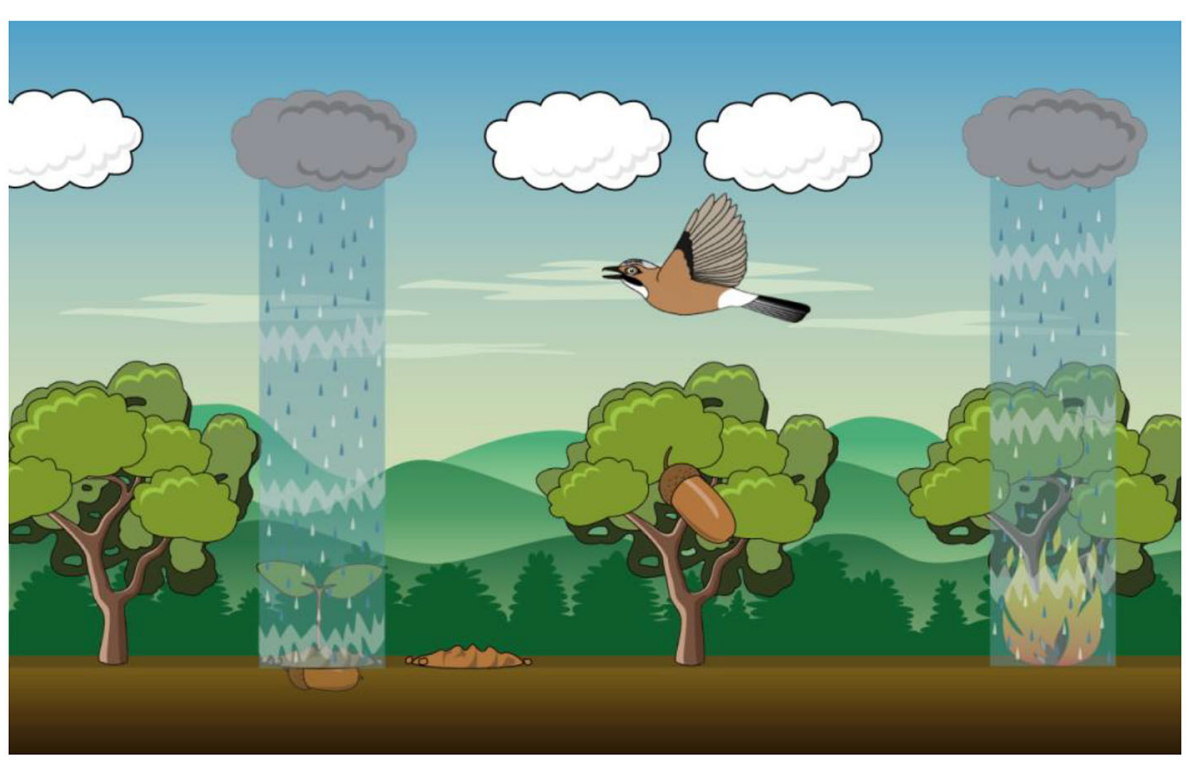

FIGURE 8 | Game of the Jay (Santos et al., 2017).

to be able to associate each footprint to their species as quickly as possible by revealing them two at a time (Figure 10).

Focusing on the need to increase awareness for behavior change, the Invasive Plants game (Santos et al., 2018) is a serious game to inform and raise awareness about invasive plant species in Portugal (Figure 11). It makes the visitor aware of the proper way of removing invasive species so that they will not spread throughout the local ecosystem, disrupting it, and avoiding damaging the ecosystem with those measures. The main goal of the game is to remove invasive plants, which consume all the oxygen from the lake's water and, due to their fast reproductive rate, can prevent sunlight from reaching the underwater flora. A user-centered design approach was used to develop the prototype, maximizing the usability and the fun factor, while keeping the educational content effective. This was performed through two iterations, including respectively 33 users in the first iteration and 30 users in the second. As a result of this process, the perception that the message of the game was clear increased from 75 to $83 \%$, and the effectiveness of the science communication component increased from 76 to $80 \%$. About the fun factor, the percentage of users that found the game fun increased from 48 to $80 \%$. Overall, there is a need to introduce a user-centered approach in the development of this type of game to ensure the effectiveness of the science communication and fun in the game. The use of user-centered design is very important to achieve the goals on pervasive games. The main reason is that it values the needs and the critical opinions of the users to design the best opportunities to challenge them without disrupting the user experience of the contact with the surrounding environment. 


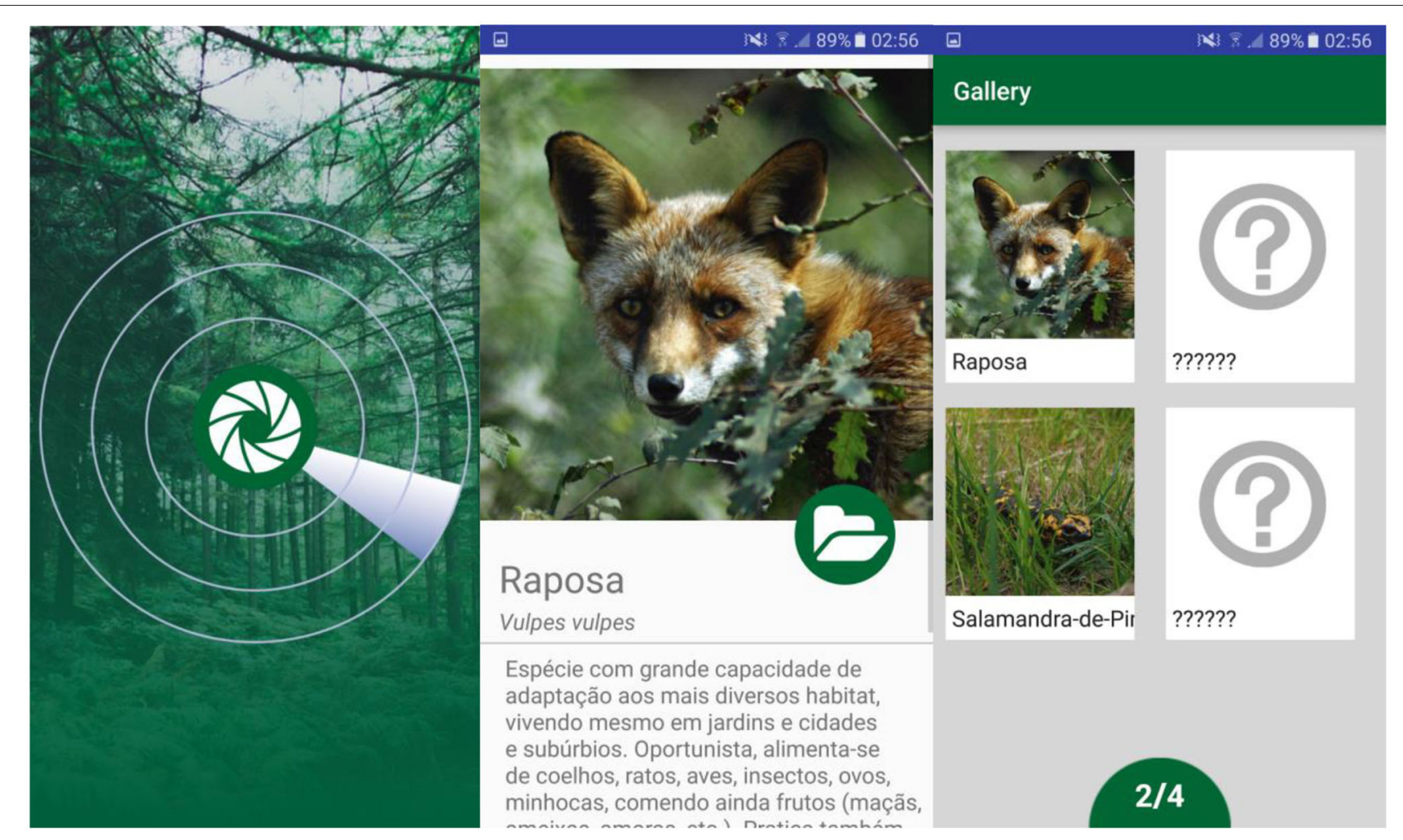

FIGURE 9 | The Virtual Animal Detector (Santos et al., 2016).

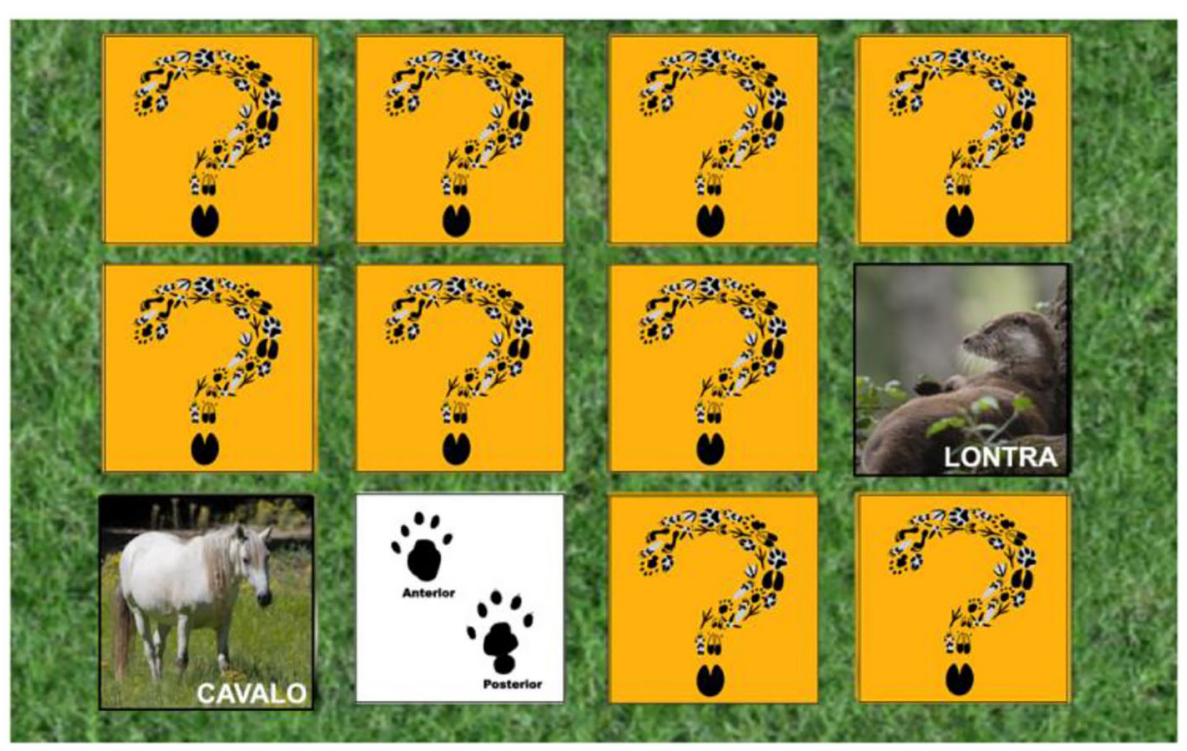

FIGURE 10 | Footprints Memory game (Santos et al., 2017).

To further extend the pervasiveness of the games, Augmented Reality was introduced in a new game-Birds of Prey (Santos et al., 2020). The purpose of this mini-game is to engage the visitors to spot augmented birds of prey flying above them and guess the species' name based on the birds' silhouette. When a bird is selected for the first time, it will be immediately unlocked 


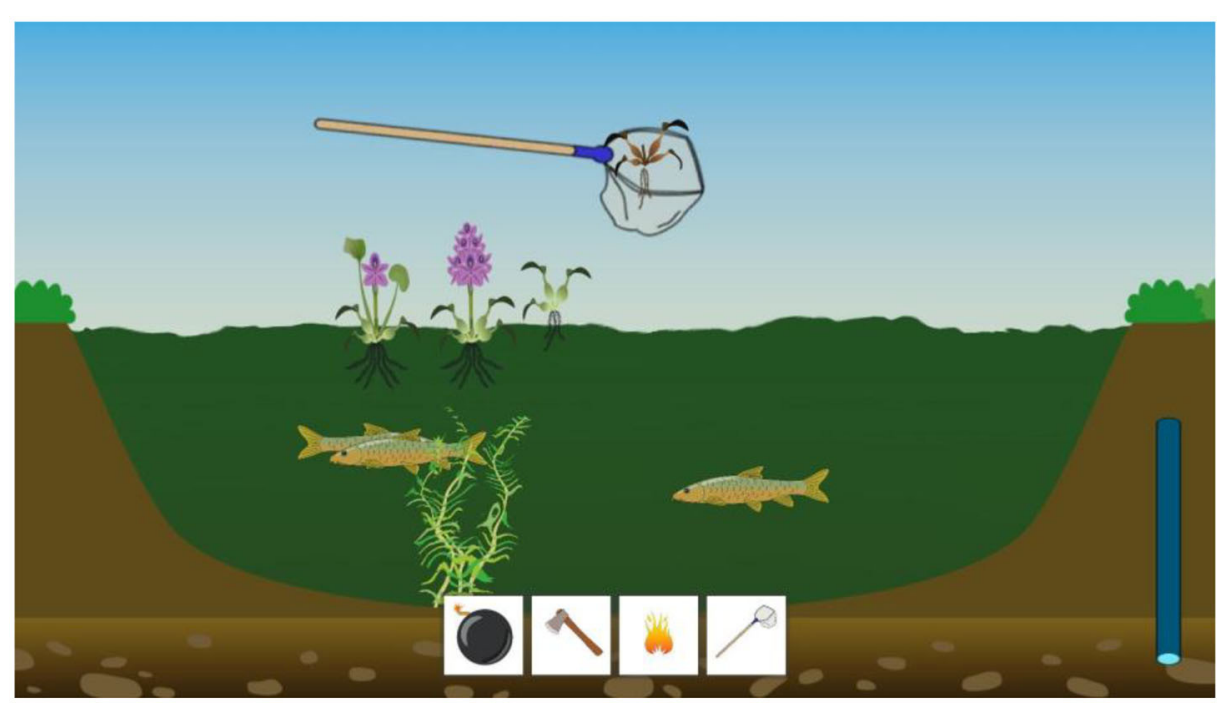

FIGURE 11 | The Invasive Plants game (Santos et al., 2018).

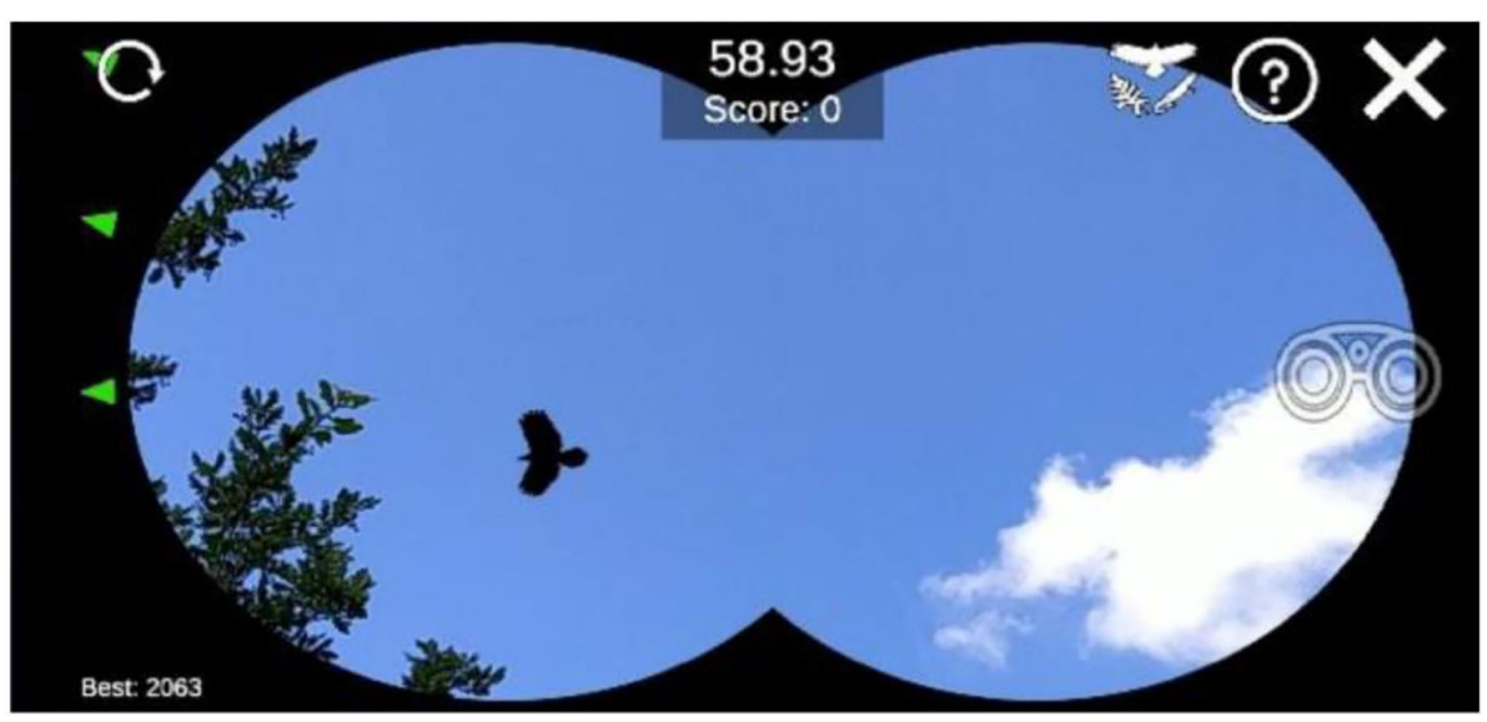

FIGURE 12 | The Birds of Prey game-binocular view (Santos et al., 2020).

and added to the collectibles board. The player then can access the Collectibles and view more information about the newly discovered bird. The game has an option to use binoculars that, when activated, will zoom in the game (as real binoculars), as can be observed in Figure 12. This in-game feature makes it easier to observe the differences between the birds' silhouettes.

A total of 34 volunteers participated in the evaluation of this prototype, where a simple questionnaire was introduced, with a 1-5 Likert scale. A median of 5 was obtained for fun and visuals and a median of 4 for the usability of the game. As expected, the introduction of Augmented Reality in pervasive games increases engagement and usability.
The Game of the Jay (Santos et al., 2017), the Virtual Animal Detector (Santos et al., 2016), the Footprints Memory (Santos et al., 2017), Invasive Plants (Santos et al., 2018), and Birds of Prey (Santos et al., 2020) are some examples of game prototypes for a nature park. Each explores different mechanics and pervasiveness on science communication and environmental awareness. The goal with these games is to amplify and enrich the experience of visiting natural parks, augmenting our perception of the natural world so we can better understand it and protect it. Nevertheless, these examples of Serious Pervasive Games can be pushed to other areas and explored for other educational contexts or behavior change. 


\section{ISSUES IN SERIOUS PERVASIVE GAMES}

Serious games development has been studied, and some guidelines have already been proposed for learning and training effectiveness (Catalano et al., 2014). Nevertheless, for serious pervasive games, several additional issues must be taken into consideration, such as the previous work on location-based games (Jacob and Coelho, 2011). These issues can affect all magic circle expansions (Spatial, Temporal, and Social) (Nevelsteen, 2015). For instance, the player may be at a location unsuitable for the game (lack of geo-referenced content in the game), or the time of play may be inappropriate (bad weather, incorrect or inadequate time of day to play the game) or the player may lack companions or adversaries to play the game with (no other players physically present). While some of these issues are minor and could be addressed through adaptivity mechanisms or procedural content generation, other issues may pose health or safety concerns (Jacob et al., 2017). Specifically, techniques such as Action Prediction (McGee and Abraham, 2010), Player Modeling (Yannakakis et al., 2013), Adaptive Pacing (Thompson, 2014), Dynamic Game Difficulty Adjustment (Hawkins et al., 2012), and Learning Classifier Systems (Shafi and Abbass, 2017) have been applied successfully to games and could also be adapted to pervasive games to help mitigate some of these issues.

From the learning design perspective to the game design, the following subsections describe the main issues encountered.

\section{Learning Design Issues}

An issue impacting the use and dissemination of serious pervasive games is their associated workload from a teacher's perspective (Marklund and Taylor, 2016). To employ such a game within the constraints of time and curriculum, teachers need to realize how it will contribute to the learning goals planned for students, and monitor how the game is progressing. It is necessary to plan ahead several deployment tasks, such as instructions for students, instruments for keeping track of progress and collecting assessment elements. After deployment, it is necessary to manage the pervasive gaming activity while it takes place, ensuring that students get adequate and timely support and feedback, that there is adequate provision for teacher regulation, self-regulation, and co-regulation of learning among peers. Once the activity is completed, it is necessary to have elements to provide adequate assessment: otherwise, teachers may resort to use pervasive games only for awareness of motivational purposes, withdrawing them from assessment or worse, conducting assessment based only on right/wrong answer or item completion, thus bypassing all the contextaware meaningful capabilities of this medium. BEACONING's approach of combining game progress and activities with learning goals in a gamified lesson path, via a triadic assessment model (Baptista et al., 2016) is a significant contribution toward this issue (Cardoso et al., 2020). However, we believe that further advances are required in extracting meaning from pervasive activities. Teachers should be able to identify students' actions as part of foreseen (or unforeseen) choreographies of events, rather than mere marks of progress or completion. This can support more contextualized live feedback, by identifying that a student is pursuing a known deadlock or a best practice, and the same rich information about actions can then be employed for much richer assessment and post-activity feedback. There are tantalizing prospects of achieving this, by pursuing the concept of virtual choreographies as units of analysis, recording, and replaying of actions, as put into practice in proof-ofconcept systems for energy consumption gamification (Cassola et al., 2017) and platform-independent virtual animations replay (Lacet et al., 2020). This is surely an issue that is necessary to be tackled for large-scale adoption of serious pervasive games.

For the design of this type of applications, some points must be considered:

1. In games-based learning, a positive feedback is required on different activities, creating a learning environment motivated by success. So, even failure must contain pertinent information that leads to learning. The success message should reinforce what has been learned.

2. Activities should be directed to in situ observation and should not involve prior knowledge of the subject. This allows one to broaden the age range of the applications, making them feasible for different groups.

3. The contents should have a simple and straightforward language using short sentences. Each activity should be limited to an idea that is in tune with the game mechanics.

4. All the information and navigation must be compatible with accessibility tools of the mobile devices (auditive speech, augmented lettering, contrast text, shortcut keys, and haptic information)

5. The objects found at the POIs must inspire, enthrall, and enlighten the player. At its core is the ability to inspire curiosity and stimulate learning.

6. Creative activities should allow the use of various tools and should have the possibility of social sharing.

Serious games must consider the different player profiles (active, passive)-explorer, collector, creative, and collaborative. They must bear in mind different game mechanics and the emotional involvement that is typical of this game typology.

\section{Game and Level Design Issues}

Since a location-based game is played in the spatial context of the player, extending the magic circle from the mobile device to the surrounding environment of the user, several relevant issues must be taken into consideration. The player must be kept safe during gameplay by avoiding dangerous places (e.g., road traffic or cliffs) or reducing the challenges' intensity in these places. This can be done by using indirect control, providing restrictions to the movement of the player, by introducing obstacles or enemies. Another consideration is that level design should be adapted to each of the players' locations or only allow for the player to play the game at the designated location. Also, there is always an unpredictability issue, considering that the environment may have changed due to construction works, events, or weather conditions. When navigation is required, intuitive navigational 
aids, such as maps or navigation cues, should be provided. Finally, user-centered design methodologies should be used to assure that the game is fun and, at the same time, keeps the effectiveness.

\section{Hardware Limitations}

Pervasive games are played through mobile devices. In locationbased games, there is a need to position the player in the functional space of the game. In outdoor locations, it is simpler to use a Global Navigation Satellite System (GNSS) compatible device, although its low accuracy needs to be taken into consideration when designing the game. If the locations of the challenges are close together, that may lead to the deployment of the wrong challenge. Therefore, a radius with a dimension appropriate to the location error margin should be considered for checking the location, based on the hardware and the interference of the surrounding environment (e.g., buildings). If higher accuracy is required, devices such as Bluetooth beacons or RFID tags can be used. This is also the case of indoor environments, where GNSS technologies do not operate.

Another critical issue is also the Internet coverage for using client/server application to support the use of the players' context in pervasive games. If $\mathrm{WiFi}$ is available, the user may need to login to a specific network. Nevertheless, since the game is played in specific places, the game developers should ensure full coverage of the game area. If this WiFi network is not available, then the user should use the cellular data network from the player's data plan. This can also bring constraints as the user may incur additional costs, or the player's operator may not provide full coverage for that area.

Players may not be willing to use their personal smartphones to play the game. Many reasons may lead to this, be the battery drain, inadequate data plan, or the memory shortage to install the app, or being afraid to install an additional app. For this latter issue, the app can be developed in HTML 5, and be executed on a web browser.

\section{Information Availability and Suitability}

Pervasive games are based on contextual information, which may not be available for several reasons. Not all parts of the globe provide access to specific information, such as geographic information (e.g., maps) or related information (e.g., weather). Furthermore, profile information may not be available.

\section{Player's Fitness and Pace}

In location-based games, the player's movement around the real world is used as an input, often to move the avatar around the game world. Not all players can walk around the same amount of distance or overcome specific obstacles that involve climbing, for example, potentially leading to situations where both the player's and bystanders' safety is at risk. From children to senior adults, there should be a way to customize games to fit the players' fitness profile or provide adaptive gameplay (Jacob et al., 2017). In intense gameplays, there should also be considered the need to make a pause or adapt the distance or pace of the game to the weather conditions, events, or disruptions that may occur.

\section{Player's Data Protection}

When playing pervasive games, there are several data that may be private to the user, such as the location and date of the games. When considering multiplayer or social games this fact could be relevant. Furthermore, pervasive apps should comply with the legislation of the place of play. Regarding the storage of this sensitive information, it is preferable to store it remotely in a server as this option provides a safer place for the player to store personal data, particularly considering how easy it is to lose a mobile phone or someone unauthorized accessing its contained information.

\section{CONCLUSION AND FUTURE CHALLENGES}

Pervasive games have a potential for engaging the user with contextual challenges, establishing a connection to the surrounding environment. Serious Pervasive Games lie at the intersection of pervasive games with serious games and raise questions on how to design for experiential learning, which by its nature implies a design that favors players' attention to both the physical domain as for the digital realm.

Serious pervasive games have a high potential for Education, particularly for problem-based learning methods. Pervasiveness can be adjusted to many conditions: from spatial contextualized games to augmented reality games, they provide distinct levels of engagement. Nevertheless, several issues should be considered when designing a pervasive game.

One of the important issues of our research is related to cocreation and the monitoring that must be given to users/creators of this type of games. In this sense, a research methodology centered on content creators is required, which will allow cocreation more focused on learning content.

The technical support of a game designer in the initial conception can be essential for the acquisition of the technology and mechanics involved in mini-games. In this sense, we will conduct workshops with focus groups to identify the monitoring needs that this type of user needs.

The creation processes, difficulties, and concerns of these creators will be identified, with the objective of creating a system based on procedures. In the future, it may be important to improve in any system that involves the creation of pervasive games and augmented reality experiences.

Another important issue concerns user personalization; that is, depending on the player's profile, the system can adapt to the mechanics that underlie it, which may prove essential in terms of user satisfaction and adequacy to the profile and needs, being particularly important in terms of accessibility.

Summarizing, the future challenges of serious pervasive games include authoring tools that facilitate the creation of pervasive content for learning or other application areas, game 
engines suitable for its development, and robust frameworks that overcome the issues reported.

\section{AUTHOR CONTRIBUTIONS}

All authors listed have made a substantial, direct and intellectual contribution to the work, and approved it for publication.

\section{ACKNOWLEDGMENTS}

This work was financed by the ERDF - European Regional Development Fund through the Operational Programme for

\section{REFERENCES}

Arango-López, J., Cerón Valdivieso, C. C., Collazos, C. A., Gutiérrez Vela, F. L., and Moreira, F. (2019). CREANDO: Tool for creating pervasive games to increase the learning motivation in higher education students. Telematics Informatics 38, 62-73. doi: 10.1016/j.tele.2018.08.005

Arango-López, J., Collazos, C. A., Velas, F. L. G., and Moreira, F. (2018). Using pervasive games as learning tools in educational contexts: a systematic review. Intern. J. Learn. Technol. 13, 93-114. doi: 10.1504/IJLT.2018. 092094

Arango-López, J., Gallardo, J., Gutiérrez, F. L., Cerezo, E., Amengual, E., and Valera, R. (2017). Pervasive games: Giving a meaning based on the player experience. ACM Intern. Conf. Proceed. Ser. Part F1311. doi: $10.1145 / 3123818.3123832$

Arnab, S., Tombs, G., Duncan, M., Smith, M., and Star, K. (2016). "Towards the blending of digital and physical learning contexts with a gamified and pervasive approach," in Games and Learning Alliance. GALA 2015. Lecture Notes in Computer Science, Vol. 9599, eds A. De Gloria and R. Veltkamp (Cham: Springer). doi: 10.1007/978-3-319-40216-1_50

Baptista, R., Coelho, A., and Vaz de Carvalho, C. (2016). "Relation between game genres and competences for in-game certification," in Serious Games, Interaction, and Simulation. Lecture Notes of the Institute for Computer Sciences, Social Informatics and Telecommunications Engineering, Vol. 161, eds C. Vaz de Carvalho, P. Escudeiro, and A. Coelho (Cham: Springer). doi: 10.1007/978-3-319-29060-7_6

Benford, S., Rowland, D., Hull, R., Reid, J., Morrison, J., Facer, K., et al. (2004). "Savannah: designing a location-based game simulating lion behavior," in International Conference on Advances in Computer Entertainment Technology. Retrieved from http://eprints.lincoln.ac.uk/659/

Bourazeri, A., Arnab, S., Heidmann, O., Coelho, A., and Morini, L. (2017). Taxonomy of a gamified lesson path for STEM education: the beaconing approach. Proc. 11th Euro. Conf. Games Based Learn. ECGBL. 1, 29-37.

Cardoso, P., Morgado, L., Coelho, A. (2020). Authoring Game-Based Learning Activities that are Manageable by Teachers. ERCIM News. 120, $17-18$.

Carvalho, A. A. A., and Guimarães, D. (2018). "The EduPARK game-like app with Augmented Reality for mobile learning in an urban park," in Atas do 4.0 Encontro sobre Jogos e Mobile Learning.

Cassola, F., Iria, J., Paredes, H., Morgado, L., Coelho, A., and Soares, F. (2017). Using Choreographies to Support the Gamification Process on the Development of an Application to Reduce Electricity Costs. Lecture Notes in Computer Science (Including Subseries Lecture Notes in Artificial Intelligence and Lecture Notes in Bioinformatics) (Springer Verlag), 256-257.

Catalano, C. E., Luccini, A. M., and Mortara, M. (2014). Guidelines for an effective design of serious games. Intern. J. Seri. Games 1. doi: 10.17083/ijsg.v1i1.8

Coelho, A., and Costa, L. M. (2017). "The integration of augmented reality and the concept of sticker album collection for informal learning in museums," in Immersive Learning Research Network. iLRN 2017. Communications in Computer and Information Science, Vol. 725, ed D. Beck et al. (Cham: Springer). doi: 10.1007/978-3-319-60633-0_9
Competitiveness and Internationalisation - COMPETE 2020 Programme and by National Funds through the Portuguese funding agency, FCT - Fundação para a Ciência e a Tecnologia within project POCI-01-0145-FEDER-030740 - PTDC/CCICOM/30740/2017. Part of this work has also been supported by the European Union's Horizon 2020 - The EU Framework Programme for Research and Innovation 2014-2020, under grant agreement No. 687676. We would also acknowledge the research grant from the Operation NORTE-08-5369-FSE-000049 supported by Norte Portugal Regional Operational Programme (NORTE 2020), under the PORTUGAL 2020 Partnership Agreement, through the European Social Fund (ESF), and also the FCT-Austin grant Ref. PD/BD/142893/2018.

Falk, J., and Davenport, G. (2004). Live Role-Playing Games: Implications for Ubiquitous Computer Game Interfaces.

Felipe, E., Massa, S., and Rico, C. A. (2018). "Pervasive Serious Game for Development Skills in Computer Networking," in 2018 IEEE Biennial Congress of Argentina (ARGENCON) (IEEE), 1-7.

Hawkins, G., Nesbitt, K., and Brown, S. (2012). Dynamic difficulty balancing for cautious players and risk takers. Intern. J. Comp. Games Technol. 2012, 1-10. doi: $10.1155 / 2012 / 625476$

Huizinga, J. (1938). Homo Ludens: Proeve Ener Bepaling Van Het Spelelement Der Cultuur. Groningen, Wolters-Noordhoff cop. (original Dutch edition - A Study of the Play-Element in Culture).

Jacob, J., and Coelho, A. (2011). Issues in the development of location-based games. Intern. J. Comp. Games Technol. 2011:7. doi: 10.1155/2011/495437

Jacob, J., Lopes, A., Nóbrega, R., Rodrigues, R., and Coelho, A. (2017). "Player adaptivity and safety in location-based games," in Advances in Computer Entertainment Technology. ACE 2017. Lecture Notes in Computer Science, Vol. 10714, eds A. Cheok, M., Inami and T. Romão (Cham: Springer), 219-238. doi: 10.1007/978-3-319-76270-8_16

Lacet, D., Penicheiro, F., Morgado, L., and Coelho, A. (2020). "Preserving story choreographies across multiple platforms: an approach to platformindependent reuse of characters' behaviors for games, simulations, animations and interactive videos," in ARTECH 2019 Proceedings (ACM). doi: $10.1145 / 3359852.3359916$

Laine, T. H., and Joy, M. (2009). Survey on context-aware pervasive learning environments. Intern. J. Interactive Mobile Technol. 3, 70-76.

Lima, C., Schlemmer, E., and Morgado, L. (2020). "Managing learning in environments where students move: a panorama of problems and contributions," in Atas do $5^{\circ}$ Encontro sobre Jogos e Mobile Learning, Centro de Estudos Interdisciplinares do Século 20 (Universidade de Coimbra, Portugal), 248-258.

Marklund, B. B., and Taylor, A. S. A. (2016). Educational games in practice: the challenges involved in conducting a game-based curriculum. Electronic J. e-Learn. 14, 122-135.

Martinez-Ortiz, I., Perez-Colado, I., Rotaru, D. C., Freire, M., and Fernandez-Manjon, B. (2019). From Heterogeneous Activities to Unified Analytics Dashboards. (Zenodo). doi: 10.1109/EDUCON.2019. 8725222

McGee, K., and Abraham, A. (2010). "Real-time team-mate AI in games: a definition, survey, and critique," in Proceedings of the Fifth International Conference on the Foundations of Digital Games (FDG'10). Association for Computing Machinery (New York, NY), 124-131. doi: $10.1145 / 1822348.1822365$

Montola, M. (2005). Exploring the edge of the magic circle: defining pervasive games. Proc. DAC 1966, 16-19.

Montola, M., Stenros, J., and Waern (2009): A. Pervasive Games: Theory and Design. Experiences on the Boundary Between Life and Play. Amsterdam: Morgan Kaufmann. doi: 10.1201/9780080889795

Nevelsteen, K. J. L. (2015). "A survey of characteristic engine features for technology-sustained pervasive games," in Springer Briefs in Computer Science (Cham: Springer). 
Nieuwdorp, E. (2007). The pervasive discourse: an analysis. Comp. Entertain. 5:13. doi: $10.1145 / 1279540.1279553$

Parker, J. (2011). "A design-based research approach for creating effective online higher education courses," in 26th Annual Research Forum: Educational Possibilities (Fremantle, WA: Western Australian Institute for Educational Research Inc; University of Notre Dame).

Pontefract, D. (2013). Flat Army: Creating a Connected and Engaged Organization. Boise, ID: Wiley.

Raessens, J. (2006): Playful identities, or the ludification of culture. Games Cult. 1, 52-57. doi: 10.1177/1555412005281779

Salen, K., and Zimmerman, E. (2004). Rules of Play: Game Design Fundamentals. Cambridge; London: The MIT Press.

Santos, L., Coelho, A., and Nóbrega, R. (2018). "Game design for environmental awareness - the case of 'Invasive Plants," in 10th Conference on Videogame Sciences and Arts - Videojogos 2018.

Santos, L., Pereira, D., Beça, P., and Coelho, A. (2017). Aplicação móvel para divulgação do património natural no turismo. Turismo Desenvolv. 27/28, 1461-1473.

Santos, L., Pereira, D., Nóbrega, R., Beça, P., and Coelho, A. (2016). Jogos sérios digitais para a promoção do património natural - o caso de um jogo de exploração de um parque na busca dos seus animais [poster + demo] [BEST DEMO\}. 33:2991.

Santos, L., Silva, L., Nóbrega, R., Almeida, R., and Coelho, A. (2020). "An interactive application framework for natural parks using serious locationbased games with augmented reality," in Proceedings of GRAPP 2020 - The International Conference on Computer Graphics Theory and Applications, (to be published). doi: 10.5220/0008947602470254

Santos, V., and Burguès, R. P. (2017). "Authoring a serious pervasive game for reflecting upon urban spaces," in Interactivity, Game Creation, Design, Learning, and Innovation, (Cham: Springer), 74-84. doi: 10.1007/978-3-319-76908-0_8

Sawyer, B., and Rejeski, D. (2002). Serious Games: Improving Public Policy Through Game-based Learning and Simulation. Washington, DC: Woodrow Wilson International Center for Scholars.

Schaal, S., Otto, S., Schaal, S., and Lude, A. (2018). Game-related enjoyment or personal pre-requisites-which is the crucial factor when using geogames to encourage adolescents to value local biodiversity. Int. J. Sci. Educ. 8, 213-226. doi: $10.1080 / 21548455.2018 .1441571$

Shafi, K., and Abbass, H. (2017). A survey of learning classifier systems in games. IEEE Comput. Intellig. Magazine, 12, 42-55. doi: 10.1109/MCI.2016.2627670
Syvänen, A., Beale, R., Sharples, M., Ahonen, M., and Lonsdale, M. (2005). "Supporting pervasive learning environments: adaptability and context awareness in mobile learning," in Proceedings of the 2005 IEEE International Workshop on Wireless and Mobile Technologies in Education (Tokushima).

Taborda, J. P., Arango-López, J., Collazos, C. A., Vela, F. L. G., and Moreira, F. (2019). Effectiveness and fun metrics in a pervasive game experience: a systematic literature review. Adv. Intellig. Syst. Comp. 932, 184-194. doi: 10.1007/978-3-030-16187-3_18

Thompson, T. (2014). In the Directors Chair: Left 4 Dead. AI and Games. Available online at: http://t2thompson.com/2014/12/01/in-the-directors-chair-left-4dead/

Valente, L., and Feijó, B. (2014). "Extending Use Cases to Support Activity Design in Pervasive Mobile Games," in Brazilian Symposium on Games and Digital Entertainment, SBGAMES, 2014-December(December), 193-201. doi: 10.1109/SBGAMES.2014.11

Valente, L., Feijó, B., and Leite, J. C. S. do P. (2017). Mapping quality requirements for pervasive mobile games. Requirem. Eng. 22, 137-165. doi: 10.1007/s00766-015-0238-y

Viana, J. R. M., Viana, N. P., Trinta, F. A. M., and De Carvalho, W. V. (2014). "A systematic review on software engineering in pervasive games development," in Brazilian Symposium on Games and Digital Entertainment, SBGAMES, 2014-Decem(December), 51-60. doi: 10.1109/SBGAMES.2014.16

Yannakakis, G. N., Spronck, P., Loiacono, D., and Andre, E. (2013). "Player modeling," in Artificial and Computational Intelligence in Games, eds S. M. Lucas, M. Mateas, M. Preuss, P. Spronck, and J. Togelius (Schloss DagstuhlLeibniz-Zentrum fuer Informatik), 45-59. Available online at: https://www.um. edu.mt/library/oar/handle/123456789/29725

Conflict of Interest: The authors declare that the research was conducted in the absence of any commercial or financial relationships that could be construed as a potential conflict of interest.

Copyright (c) 2020 Coelho, Rodrigues, Nóbrega, Jacob, Morgado, Cardoso, van Zeller, Santos and Sousa. This is an open-access article distributed under the terms of the Creative Commons Attribution License (CC BY). The use, distribution or reproduction in other forums is permitted, provided the original author(s) and the copyright owner(s) are credited and that the original publication in this journal is cited, in accordance with accepted academic practice. No use, distribution or reproduction is permitted which does not comply with these terms. 